\title{
Sistem Pendukung Keputusan Kenaikan Jabatan Fungsional dan Pangkat Dosen
}

\author{
Hartini $^{[1]}$, Feiliana Tan ${ }^{[2]}$ \\ STMIK Indonesia Banjarmasin, Jl. Panggeran Hidayatullah Banjarmasin Kalimantan Selatan \\ Program Studi Teknik Informatika ${ }^{[1][2]}$ \\ hartini@stmik.id ${ }^{[1]}$, feilianatan@ stmik.id ${ }^{[2]}$
}

\begin{abstract}
One of the requirements as a lecturer is to have functional positions of lecturers and lecturers. And every 2 years must apply Functional increase and rank lecturer. Because it is a lecturer performance parameter. The periods and rules for the improvement of functional and lecturer functionalities have been set out in Permenpan and RB no. 17 Year 2013 JO No 46 Year 2013. For that need the existence of management and services from the College to monitor the lecturers to be in a timely manner to perform functional position and lecturer rank. To support the above, it is necessary supporting technology that is able to assist services in Higher Education. The technology is a decision support system that can be used to help promote the promotion of functional positions of lecturers and lecturers. In the Decision Support System using TOPSIS method that helps sorting promotion of functional promotion of lecturer and lecturer rank. For system analysis using Flowchart system and Data Flow Diagram (DAD). With this decision support system, universities can monitor the performance of lecturers based on the improvement of functional positions of lecturers and lecturers.
\end{abstract}

Keywords-- Decission Support Sistem, Flowchart, Data Flow Diagram (DFD), TOPSIS

\section{Pendahuluan}

Berbicara tentang kenaikan jabatan fungsional dan pangkat dosen merupakan yang penting untuk lebih diperhatikan, karena seluruh dosen dipacu untuk terus bisa mengajukan kenaikan jabatan fungsional dan pangkatnya secara berkala sampai mencapai jenjang yang paling tinggi. Hal tersebut merupakan salah satu kewajiban bagi seorang pengajar / dosen dalam menjalankan tugas sesuai dengan Tri Dharma Perguruan Tinggi.

Tiap-tiap periode sistem pengajuan kenaikan jabatan dosen mulai mengalami perbaikan, yang dulu dengan ssstem offline sekarang pemerintah sudah membangun sistem pengajuan kenaikan jabatan secara online. Namun permasalahan yang dihadapi saat ini adalah pemantauan jenjang kenaikan jabatan fungsional dan pangkat dosen di masing-masing di Peguruan Tingginya. Masih banyak dosen yang lebih dari 2 tahun belum mengajukan kenaikan jabatan fungsional dan pangkatnya. Hal tersebut tentunya akan mempengaruhi kinerja dari masing-masing Perguruan Tinggi tersebut.

Dari permasalahan tersebut diatas, maka perlu adanya Sistem Pendukung Keputusan yang dapat membantu Perguruan Tinggi untuk memantau dosen-dosen yang akan mengajukan kenaikan jabatan fungsional dan pangkatnya. Dalam Sistem Pendukung Keputusan tersebut menggunakan metode Technique for Order Preference by Similarity to Ideal Solution (TOPSIS) untuk merekomendasikan urutan dosen yang mengajukan kenaikan pangkat dan jabatan fungsional dosen.

Maka dalam penelitian ini diangkat judul Perancangan "Sistem Pendukung Keputusan Kenaikan Jabatan Fungsional dan Pangkat Dosen". Diharapkan dengan adanya sistem ini dapat membantu Perguruan Tinggi dalam mamantau dosen-dosennya dalam hal pengajuan kenaikan jabatan fungsional dan pangkat dosen.

\section{LANDASAN TEORI}

\section{A. Sistem Pendukung Keputusan}

Sistem Pendukung Keputusan merupakan sistem informasi pemodelan, dan pemanipulasian data (Kusrini,2007). Sistem itu digunakan untuk membantu pengambilan keputusan dalam situasi yang semiterstruktur dan situasi yang tidak terstruktur, dimana tidak seorang pun tahu bagaimana keputusan seharusnya di buat, yaitu :

1. Subsistem Manajemen Data

2. Subsistem Manajemen Model

3. Subsistem Antarmuka Pengguna

Subsistem Manajemen Berbasis Pengetahuan

Arsitektur sistem pendukung keputusan ditunjukkan pada gambar 2.1 berikut : 


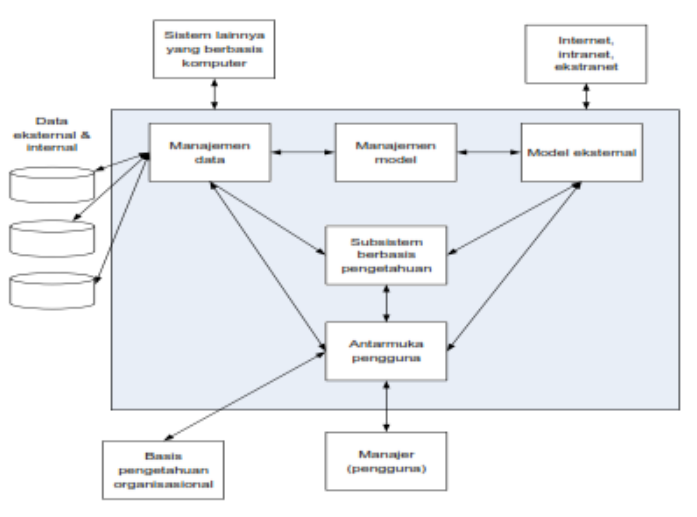

Gambar 1 Arsitektur Sistem Pendukung Keputusan

\section{B. Komponen Sistem Pendukung Keputusan}

Suatu SPK memiliki tiga subsistem utama yaitu subsistem manajemen basis data, subsistem manajemen basis model dan subsistem perangkat lunak penyelenggara dialog (Hasan, 2002:32)

a. Subsistem Manajemen Basis Data

Kemampuan yang dibutuhkan dari manajemen basis data antara lain :

1. Kemampuan untuk mengkombinasikan berbagai variasi data melalui pengambilan dan ekstraksi data.

2. Kemampuan untuk menambahkan sumber data secara mudah dan cepat.

3. Kemampuan untuk menggambarkan struktur data logikal sesuai dengan pengertian pemakai sehingga pemakai mengetahui apa yang tersedia dan dapat menentukan kebutuhan penambahan dan pengurangan.

4. Kemampuan untuk menangani data secara personil sehingga pemakai dapat mencoba berbagai alternatif pertimbangan personil.

5. Kemampuan untuk mengelola berbagai variasi data.

b. Subsistem Manajemen Basis Model

Kemampuan yang dimiliki subsistem basis model meliputi:

1. Kemampuan untuk menciptakan model-model baru secara cepat dan mudah.

2. Kemampuan untuk mengakses dan mengintegrasikan model-model keputusan.

3. Kemampuan untuk mengelola basis model dengan fungsi manajemen yang analog dan manajemen basis data (seperti mekanisme untuk menyimpan, membuat dialog, menghubungkan dan mengakses model).

c. Subsistem Perangkat Lunak Penyelenggara Dialog

Fleksibilitas dan kekuatan karakteristik SPK timbul dari kemampuan interaksi antara sistem dan pemakai yang dinamakan subsistem dialog. Subsistem dialog dapat dibagi menjadi tiga bagian yaitu bahasa aksi (papan ketik, panel sentuh, joystick, perintah suara dan sebagainya), bahasa tampilan (printer, layar tampilan, grafik, keluaran suara dan sebagainya) dan basis pengetahuan (kartu referensi, buku manual dan sebagainya). Kombinasi dari kemampuan - kemampuan di atas terdiri dari apa yang disebut gaya dialog, misalnya meliputi pendekatan tanya dan jawab, bahasa perintah, menu dan mengisi tempat kosong. Kemampuan yang harus dimiliki oleh SPK untuk mendukung dialog pemakai/sistem meliputi:

1. Kemampuan untuk menangani berbagai variasi gaya dialog.

2. Kemampuan untuk mengakomodasi tindakan pemakai dengan berbagai peralatam masukan.

3. Kemampuan untuk menampilkan data dengan berbagai variasi format dan peralatan keluaran.

Kemampuan untuk memberikan dukungan yang fleksibel untuk mengetahui basis pengetahuan pemakai.

\section{Technique for Order Preference by Similarity to Ideal Solution (TOPSIS)}

Metode TOPSIS adalah salah satu metode untuk pengambilan keputusan multi kriteria yang pertama kali diperkenalkan oleh Yoon dan Hwang pada tahun 1981. Konsep dari alternative yang dipilih oleh TOPSIS merupakan alternatif terbaik yang memiliki jarak terpendek dari solusi ideal positif dan jarak terjauh dari solusi ideal negatif.

Metode ini digunakan karena konsepnya sederhana, mudah dipahami, komputasinya efisien dan memiliki kemampuan untuk mengukur kinerja relatif dari alternativealternatif keputusan (Yanti \& Rahmadani,2014).

Keuntungan dari metode TOPSIS adalah sebagai berikut (Jiang-jiang, 2009)

1. Metode TOPSIS merupakan salah satu metode yang simple dan konsep rasional yang mudah dipahami.

2. Metode TOPSIS mampu untuk mengukur kinerja relative dalam bentuk form matematika sederhana

3. Metode TOPSIS sesuai digunakan untuk aktifitas perangkingan data dari beberapa alternatif yang ada.

\section{Perangkat Ananlisis, Perancangan dan Implementasi Sistem}

Perangkat dan teknik yang digunakan untuk membantu menganalisa, merancang dan mengimplemtasi sistem meliputi :

1. Normalisasi Data

Normalisasi diartikan sebagai sutu teknik yang menstrukturkan / memecah / mendekomposisi data dalam cara-cara tertentu untuk mencegah timbulnya permasalahan pegolahan data dalam basis data, permasalahan yang dimaksud adalah adanya kerangkapan data (redudansi data) (Sutanta,2004).

2. Database Relational

Data relasional adalah kumpulan relasi dengan nama relasi yang jelas). Misalnya database Kalurahan dengan relasi yang dinamakan penduduk, sirkulasi dan pembuatan surat keterangan/pengantar. Relasi ini dapat dibagi menjadi tiga jenis yaitu : 
1. One-to-One

Sebuah relasi dikatakan one-to-one bila sebuah record pada tabel $A$ berhubungan tepat dengan hanya satu record di tabel $\mathrm{B}$, begitu pula sebaliknya.

2. One-to-Many

Relasi dikatakan one-to-many bila sebuah record pada tabel A dapat berhubungan dengan satu atau lebih record di tabel $\mathrm{B}$, tetapi satu record di tabel B hanya dapat berhubungan dengan tepat satu record di tabel A.

3. Many-to-Many

Sebuah relasi dikatakan many-to-many bila sebuah record pada tabel A berhubungan dengan lebih dari satu record di tabel B, demikian pula sebaliknya.

3. Data Flow Diagram (DFD)

Data Flow Diagram (DFD) merupakan alat yang digunakan untuk menggambarkan suatu sistem yang telah ada atau sistem baru yang akan dikembangkan secara logika tanpa mempertimbangkan lingkungan fisik dimana data tersebut mengalir ataupun lingkungan fisik dimana data tersebut akan disimpan (Jogiyanto, 2010)

4. Flowchart

Flowchart atau bagan alir adalah bagan (chart) yang menunjukkan alir (flow) didalam program atau prosedur sistem secara logika. Jenis flowchart yang digunakan adalah sistem flowchart dan program flowchart. Sistem flowchart merupakan bagan yang menunjukkan arus pekerjaan secara keseluruhan dari sistem.

5. Metadata dan Pembatas Integritas

Metadata adalah data mengenai data dalam file atau basisdata. Metadata atau biasa disebut dengan kamus data di dalamnya mendeskripsikan nama yang diberikan dan panjang yang ditentukan dari setiap item data. Metadata juga mendiskripsikan panjang dan komposisi setiap record.

Integritas dimaksudkan sebagai suatu sarana untuk meyakinkan bahwa data-data yang tersimpan dalam basis data selalu berada pada kondisi yang benar (tipe dan ukuran datanya), up to date (sesuai dengan kondisi aktual), konsisten (Sutanta,2004). Pembatas Integritas adalah aturan yang memaksa perubahan dan penghapusan record dan membantu menjaga data dalam keakuratan basisdata.

\section{E. Pengertian Pangkaat Dosen}

Kenaikan pangkat dosen adalah penghargaan yang diberikan aras prestasi kerja dan pengabdian Dosen terhadap suatu Perguruan Tinggi atau Universitas.

Dalam penyusunan kebijakan pengangkatan pangkat, Perguruan Tinggi mengikuti beberapa prosedur yaitu :

1) Memiliki kualifikasi akademi minimum yang diperoleh melalui pendidikan tinggi terakreditasi sesuai bidang keahliannya yaitu:

a. lulusan program magister untuk program diploma/ sarjana b. lulusan program doktor untuk program pascasarjana

2) Menduduki jenjang jabatan akademik berdasarkan keputusan pejabat yang berwenang.

Jenjang Jabatan dan Pangkat Dosen

Menurut Permenpan dan RB No 17 Than 2013 JO NO.46

Tahun 2013, Jenjang Jabatan dan Pangkat Dosen adalah sebagai berikut :

\begin{tabular}{|c|c|c|c|c|}
\hline \multirow{2}{*}{ No } & \multirow{2}{*}{$\begin{array}{l}\text { Jenjang } \\
\text { Jabatan }\end{array}$} & \multirow{2}{*}{$\begin{array}{c}\text { Jenjang } \\
\text { Pangkat/Golongan }\end{array}$} & \multicolumn{2}{|c|}{$\begin{array}{c}\text { Angka Kredit Yang Di } \\
\text { Persyaratkan }\end{array}$} \\
\hline & & & $\begin{array}{l}\text { Komulatif } \\
\text { Minimal }\end{array}$ & Perjenjang \\
\hline 1 & $\begin{array}{l}\text { Aisten } \\
\text { Ahli }\end{array}$ & $\begin{array}{l}\text { Penata Muda Tk.I, } \\
\text { III/b }\end{array}$ & 150 & - \\
\hline \multirow{2}{*}{2} & \multirow{2}{*}{ Lektor } & Penata, III/c & 200 & 50 \\
\hline & & Penata Tk. I, III/d & 300 & 100 \\
\hline \multirow{3}{*}{3} & \multirow{3}{*}{$\begin{array}{l}\text { Lektor } \\
\text { Kepala }\end{array}$} & Pembina, IV/a & 400 & 100 \\
\hline & & Pembina Tk.I, IV/b & 550 & 150 \\
\hline & & $\begin{array}{l}\text { Pembina Utama } \\
\text { Muda, IV/c }\end{array}$ & 700 & 150 \\
\hline \multirow[b]{2}{*}{4} & \multirow[b]{2}{*}{$\begin{array}{l}\text { Guru } \\
\text { Besar }\end{array}$} & $\begin{array}{l}\text { Pembina Utama } \\
\text { Madya, IV/d }\end{array}$ & 850 & 150 \\
\hline & & $\begin{array}{l}\text { Pembina Utama, } \\
\text { IV/e }\end{array}$ & 1.050 & 200 \\
\hline
\end{tabular}

\section{Metodologi Penelitian}

A. Kerangka Pemikiran

Penelitian ini menggunakan kerangka pemikiran sebagai berikut :

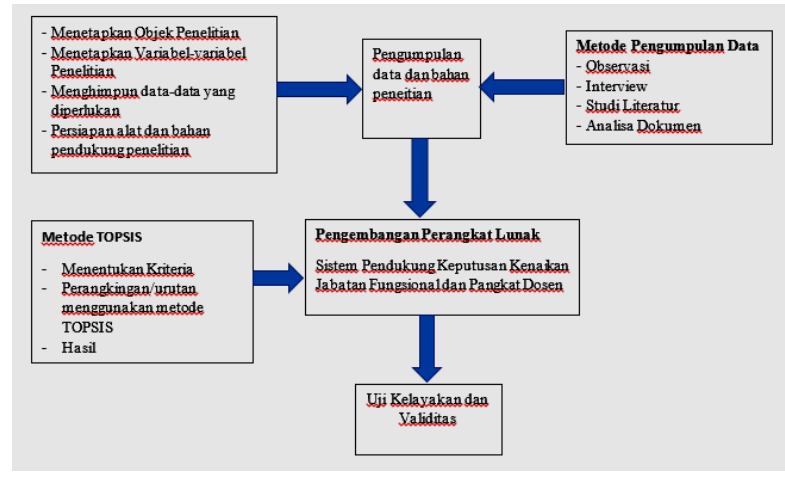

Gambar 2 Kerangka Pemikiran Penelitian

\section{B. Pengumpulan Data}

Agar mendapatkan data serta informasi yang tepat, lengkap maka dalam kegiatan pengumumpulan data digunakan beberapa teknik pengumpulan data sebagai berikut : 


\section{1) Observasi}

Merupakan kegiatan pengamatan langsung dari suatu kejadian yang sedang dilakukan (Jogiyanto,2010). Pengamatan secara langsung kepada subjek-subjek yaitu dalam hal pendokuemtasian dokumen-dokumen kenaikan jabatan fungsional dan pangkat dosen.

2) Wawancara

Wawancara adalah proses memperoleh keterangan untuk tujuan penelitian dengan cara tanya jawab sambil bertatap muka antara pewawancara dengan responden.

Data yang diperoleh dari kedua metode di atas adalah data primer yaitu data yang diperoleh secara langsung dari obyek penelitian (Masngudi, 2000). Data primer yang diperoleh berupa kondisi manajemen kalurahan yang diwujudkan dalam struktur organisasi, data penduduk dan prosedur-prosedur pelayanan kepada masyarakat dan aliran informasi yang ada di kalurahan khususnya kalurahan Nglebak sebagai tempat penelitian. Data sekunder yakni data yang diperoleh secara tidak langsung dari obyek penelitian (Masngudi, 2000). Data ini berupa keterangan-keterangan yang sudah ada serta tersusun di kalurahan seperti format pencatatan data penduduk, laporan statistik jumlah penduduk, format surat pengantar atau keterangan untuk berbagai kepentingan masyarakat.

\section{Analisis Sistem}

Ada berbagai faktor yang mempengaruhi kenaikan jabatan dan pangkat dosen. Semua faktor tersebut tergantung pada beberapa hal. Yang pertama adalah presentase yang harus dipenuhi oleh dosen yang mengajar pada program pendidikan akademik untuk masing-masing kegiatan adalah :

a. Memperoleh dan melaksanakan pendidikan dan pengajaran sekurang-kurangnya $30 \%$

b. Melaksanakan penelitian sekurang-kurangnya $25 \%$

c. Melaksanakan pengabdian kepada masyarakat sebanyak-banyaknya $15 \%$

d. Melaksanakan kegiatan penunjang Tridharma Perguruan Tinggi sebanyak-banyaknya 20\%

Dari ketentuan diatas maka dapat di tentukan kritera dalam peneitian ini adalah sebagai berikut :
a. K1: Jenjang Jabatan
b. K2: Jenjang Pangkat/golongan
c. K3: Angka Kredit

\section{Tools Pengembangan Sistem}

\section{Flowchart Sistem}

a. Bagan Alir Data Dosen

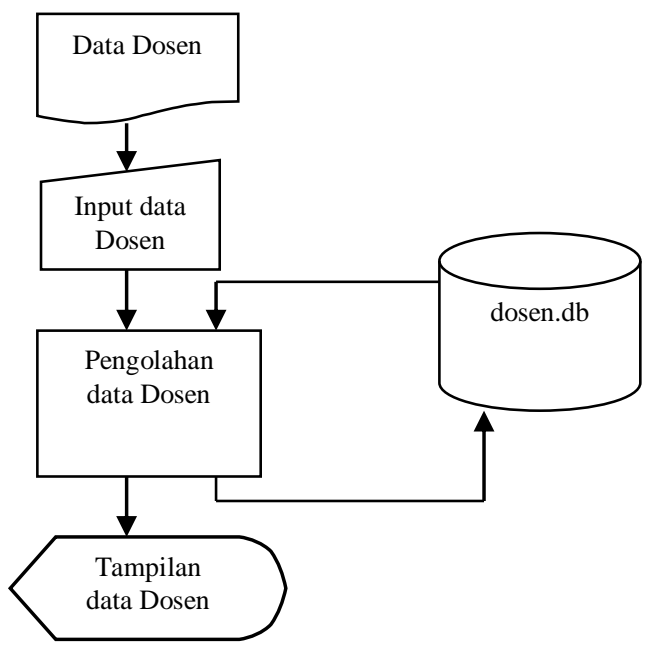

Gambar 3. Bagan alir pengolahan data Dosen.

Pada gambar 3 menjelaskan perekaman data dosen yang ada di Perguruan Tinggi. Setelah di input data tersebut akan dimasukkan ke dalam table data dosen, selanjutnya dapat di tampilkan pada layer monitor.

b. Bagan Data Kelengkapan Angka Kredit

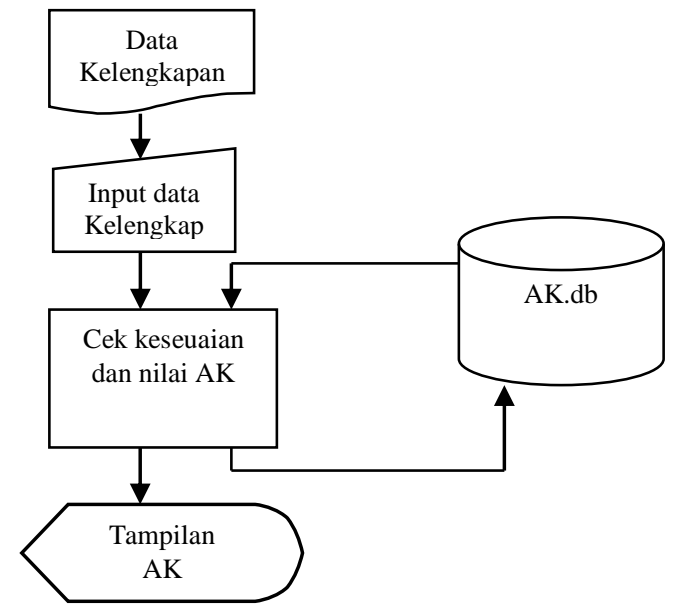

Gambar 4. Bagan alir pengolahan data Kelengkapan Angka Kredit

Gambar 4 mengambarkan perekaman data kelengkapan dokumen pengajuan kenaikan jabatan fungsional dan pangkat dosen dan nilai dari angka kreditnya. Data kelengkapan diinput secara otomatis akan keluar nilai angka kreditnya, selanjutnya total angka kredit yang dperoleh akan disimpan ke dalam storage AK. 
c. Bagan Alir Data Kriteria

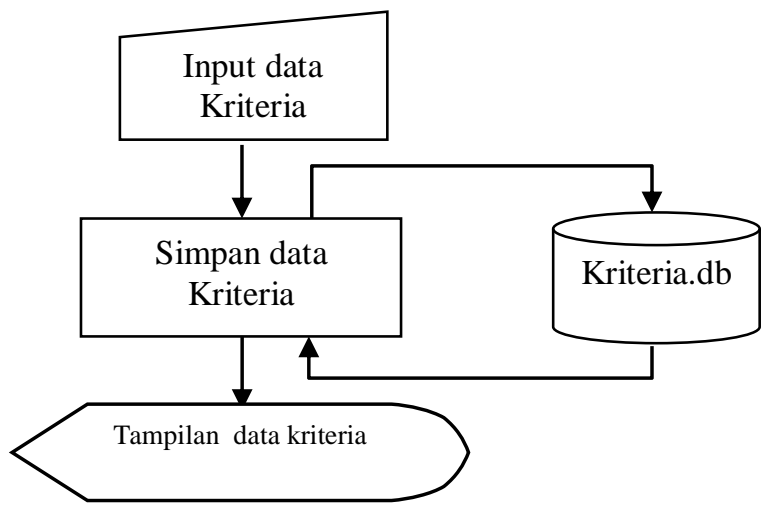

Gambar 5. Bagan Alir Data Kriteria

Bagan Alir data kriteria disini mengambarkan penyimpanan dokumen kriteria dari Sistem Pendukung Keputusan. Dimana kritera tersebut meliputi jenjang jabatan, jenjang pangkat/golongan dan angka kredit.

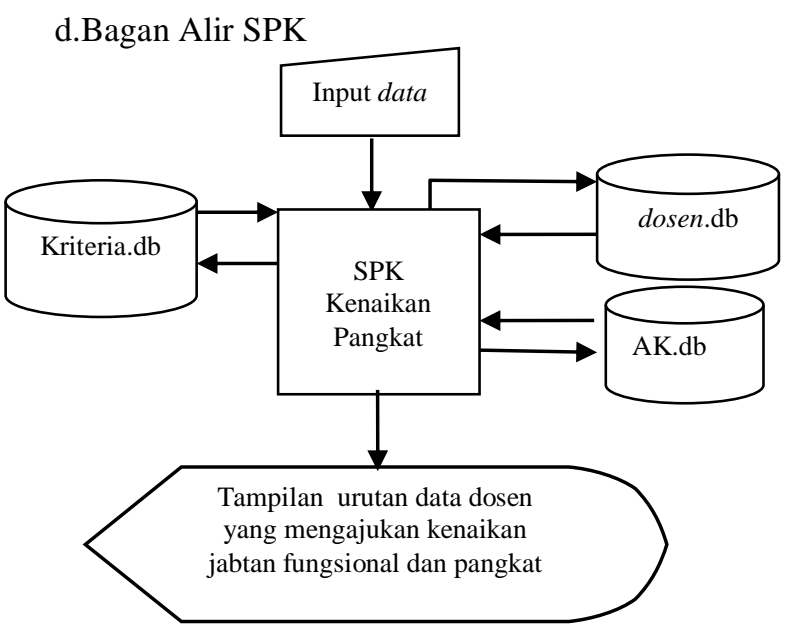

Gambar 6. Bagan alir SPK

Gambar 6 mengambarkan aliran sistem dimana saat data dosen dimasukkan akan langsung terlihat jenjang jabatan dan pangkat/golongan serta nilai angka kredit yang telah diperoleh. Dan sistem akan dengan sendirinya mengurutkan data dosen yang harus segera mengajukan kenaikan jabatan fungsional dan pangkat nya berdasarkan kriteria yang telah di tentukan yaitu jenjang jabatan, jenjang pangkat/golongan dan nilai angka kreditnya

\section{Data Flow Diagram}

d. Diagram Konteks

Diagram konteks dibuat untuk menentukan lingkup proyek awal. Sistem Pendukung Keputusan ini memiliki external entity meliputi Pegawai BAU dan Ketua Perguruan Tinggi dan Dosen. Diagram konteks sebagai berikut :

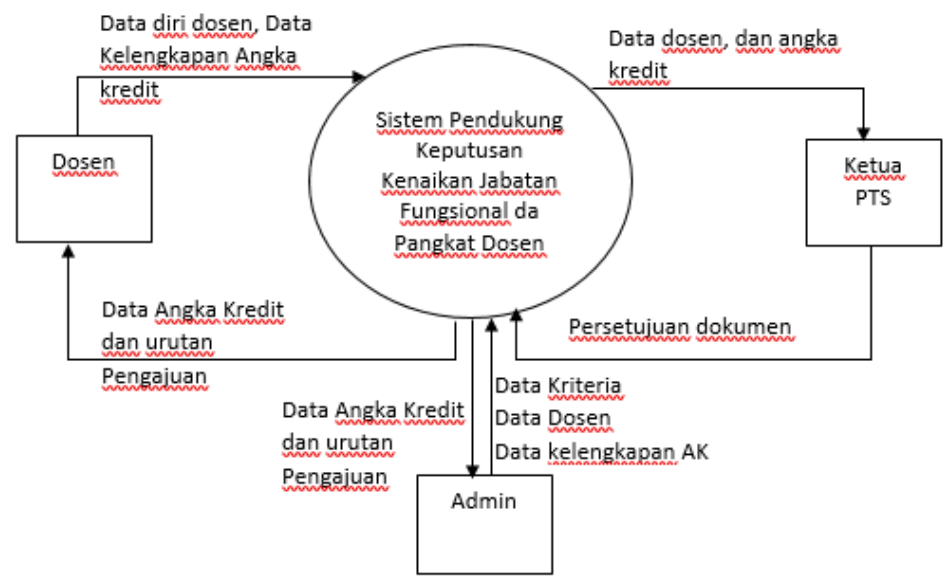

Gambar 7 Diagram Konteks Sistem Pendukung Keputusan

Kenaikan Jabatan Fungsional dan Pangkat Dosen

Diagram konteks SPK Kenaikan Jabatan Fungsional dan Pangkat Dosen, digambarkan entitas dari sistem tersebut ada 2 yaitu pegawai selaku user dari sistem dan ketua PTS selau yang mengesahkan dokumen dan menyetujui pengajuan kenaikan jabatan fungsional dan pangkat dosen. Dimana data dosen baik data diri maupun data kelengkapan angka kredit yang menginputkan ke dalam sistem adalah pegawai yang ditunjuk, selanjutnya sistem akan memproses dan menghasilkan urutsn data dosen yang akan mengajukan kenaikan jabatan fungsional dan pangkat. Hasil tersebut akan di sahkan oleh ketua PTS.

e. Diagram level 0

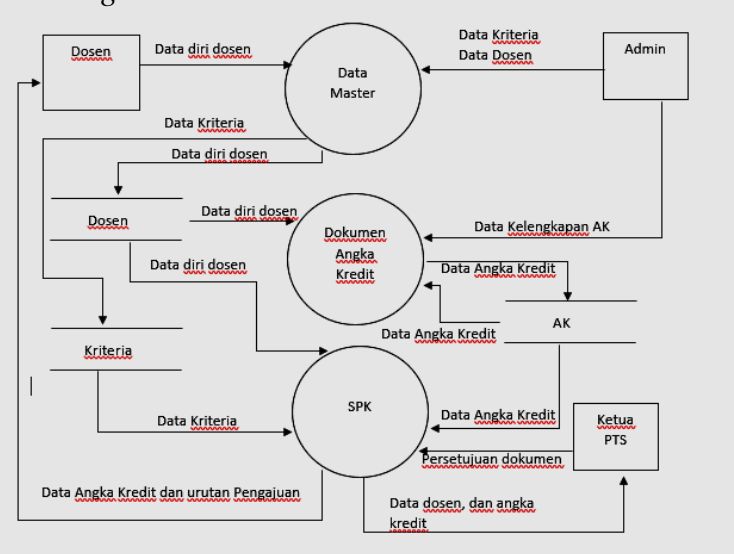

Gambar 8 Diagaram Level 0 Sistem Pendukung Keputusan Kenaikan Jabatan Fungsional dan Pangakat Dosen 
Diagaram Level 0 diatas menjelaskan dalam Sistem Penduung Keputusan Kenaikan Jabatan Fungsional dan Pangkat Dosen, terdiri dari tiga proses yaitu proses untuk penyimpanan master data yang berupa data dosen dan data kriteria, proses dokumen kelengkapan Angka Kredit yang mana dari proses ini nanti akan di peroleh total angka kredit yang sudah dicapai oleh masing-masing dosen, dan terakhir adalah sistem pendukung keputusan itu sendiri yang nantinya dalam proses tersebut akan di tampilkan urutan dosen yang akan mengajukan kenaikan jabatan fungsional dan pangkat berdasarkan kriteria yang telah ditetapkan. Agar dapat lanjut diajukan ke level berikutnya maka ketua PTS disini berfungsi untuk memberikan persetujuan terhadap dokumen yang layak untuk dilanjutkan pengajuannya.

\section{E. Relasi Antar Table}

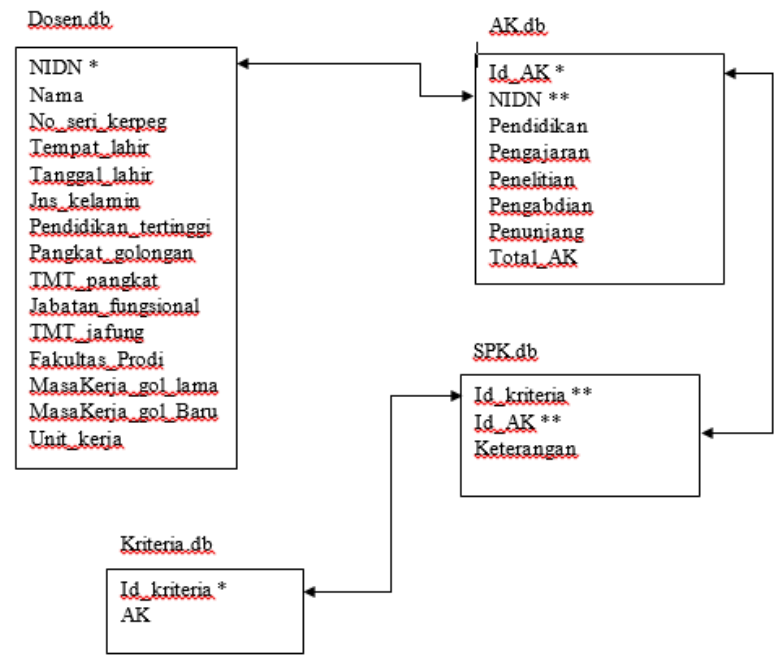

Gambar 9 Relasi Antar Table

\section{F. Rancangan Antar Muka}

a. Tampilan Layar Menu Utama

\begin{tabular}{|lcc|}
\hline MENUUTAMA & - & $\square$ \\
File Kelengkapan SPK Keluar & & \\
\hline
\end{tabular}

\section{SISTEM PENDUKUNG KEPUTUSAN} KENAIKAN JABATAN FUNGSIONAL DAN PANGKAT DOSEN

Gambar 10. Tampilan Layar Menu Utama
Pada menu utama terdiri dari menu File yang berisi data dosen dan data kriteria, menu Kelengkapan , menu SPK dan menu keluar.

b. Tampilan layer Data Dosen

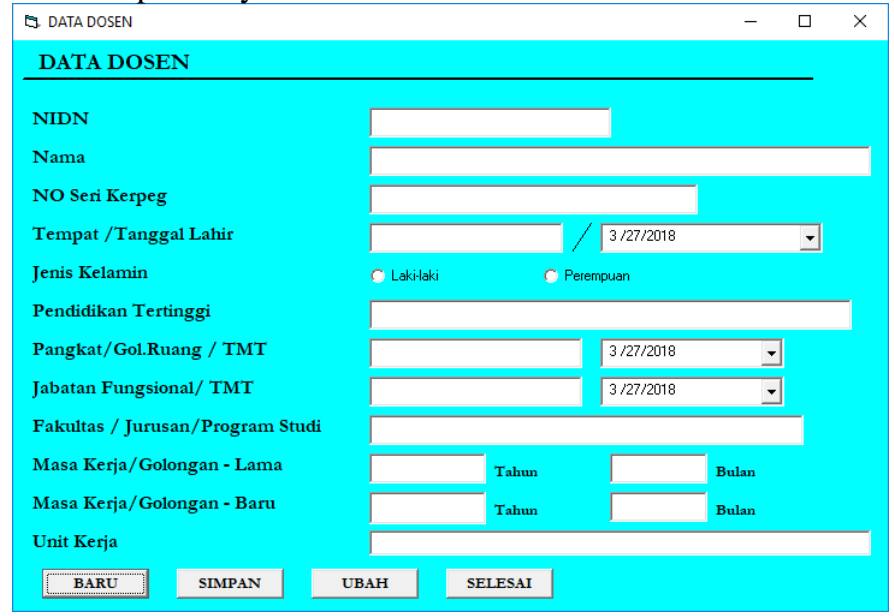

Gambar 11 Tampilan Layar Data Dosen

Gambar 11 merupakan tampilan layer untuk menginput data dosen. Proses pada form tersebut terdiri dari proses data baru, simpan data, ubah data dan selesai.

c. Tampilan Layar Data Kriteria

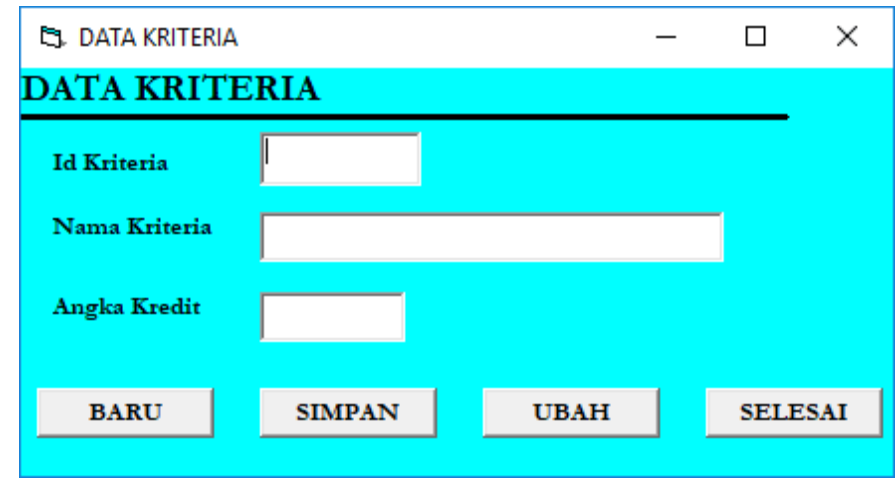

Gambar 12 Tampilan Layar Data Kriteria

Gambar 12 berfungsi untuk menginput data kriteria yang akan digunakan untuk mengurutkan peringkat dosen yang akan mengajukan kenaikan jabatan fungsional dan pangkat. 
d. Tampilan Layar Kelengkapan

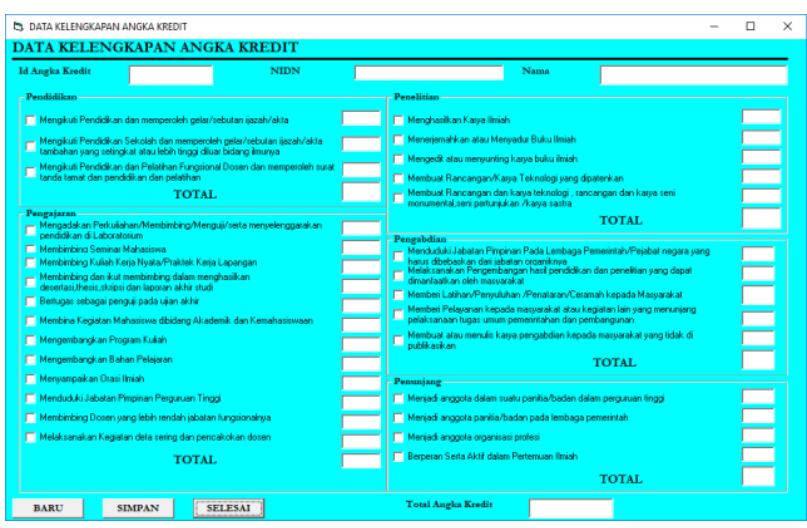

Gambar 13 Tampilan Layar Kelengkapan

Form Kelengkapan angka kredit berfungsi untuk mendokuentasikan capaian angka kredit masing-masing dosen. Selanjutnya data akan diguanakan sebgai dasar pengurutan yang berhak mengajukan kenaikan jabatan fungsional maupun yang harus mencukupi angka kredit terlebih dahulu.

e. Tampilan Layar SPK

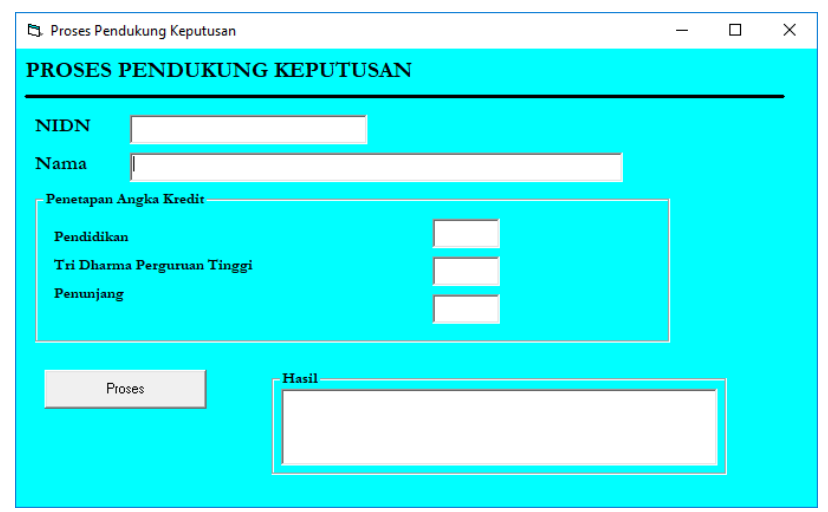

Gambar 14 Tampilan Layar SPK

Form SPK ini berfungsi untuk mengetahui apakah dosen yang bersangkutan sudah dapat mengajukan kenaikan jabatan fungsioanl dan pangkat atau harus menlengkapi dokumen untuk mencapai angka kredit yang di wajibkan.

f. Tampilan Urutan Pengajuan Jabatan Fungsional dan Pangkat Dosen

URUTAN KENAIKAN JABATAN FUNGSIONAL DAN PANGKAT DOSEN

\begin{tabular}{|c|c|c|c|c|c|}
\hline No & NIDN & Nama & $\begin{array}{c}\text { Jabatan } \\
\text { Eungsional }\end{array}$ & $\begin{array}{l}\text { Pangkat/ } \\
\text { Golongan }\end{array}$ & $\begin{array}{c}\text { Canaian } \\
\text { Angka Kredit }\end{array}$ \\
\hline 1 & 1105057404 & $\begin{array}{l}\text { Bambang } \\
\text { Lareno ST_M.Kom }\end{array}$ & $\begin{array}{l}\text { Tenaga } \\
\text { Pengaiar }\end{array}$ & - & 234.23 \\
\hline 2 & 0602048501 & Hartini.S.Kom.MKom & $\begin{array}{l}\text { Tenaga } \\
\text { Pengajar }\end{array}$ & - & 183.0 \\
\hline 3 & 029308012 & Endy Gunawan. SE.M.Kom & $\begin{array}{l}\text { Tenaga } \\
\text { Pengajar }\end{array}$ & - & 170.7 \\
\hline 4 & 1117097301 & $\begin{array}{l}\text { Liliana Swastina, } \\
\text { S.Kom.M.Kom }\end{array}$ & $\begin{array}{l}\text { Asisten Ahli } \\
(100)\end{array}$ & $\begin{array}{c}\text { Penata Muda } \\
\text { /IIIa }\end{array}$ & 164.25 \\
\hline
\end{tabular}

Gambar 15 Tampilan Urutan Pengajuan Kenaikan Jabatan Fungsional dan Pangkat Dosen

Gambar 17 menampilan hasil dari proses pengurutan dosen yang dapat melakukan pengajuan kenaikan jabatan fungsional dan pangkat.

\section{PENUTUP}

\section{A. Kesimpulan}

1. Sistem Pendukung Keputusan ini dapat digunakan untuk mendokumentasikan data-data dosen khususnya data yang berhubungan dengan jabatan dan angka kredit yang dimiliki dosen, sehingga sistem ini dapat meninformasikan data jabatan fungional dan masa kenaikan pangkat untuk dosen.

2. Sistem Pendukung keputusan ini dapat membantu pihak akademik khususnya kepegawaian dalam memantau jenjang jabatan fungsional maupun pangkat dosen, sehingga dapat mengingatkan dosen apabila sudah waktunya untuk melakukan pengajuan kenaikan jabtan fungsional dan pangkat dosen.

3. Sistem Pendukung Keputusan ini dapat memberikan kemudahan kepada dosen untuk menghitung angka kredit yang sudah diperoleh selama masa kerjanya.

\section{B. Saran}

1. Sistem ini dalam pengoperasiannya perlu diadakan pelatihan kepada user yang akan menggunakan, sehingga user akan lebih mahir dan mengetahui cara penggunaan dan perawatan terhadap sistem.

2. Sistem ini masih stand alone, perlu dikembangkan sistem online agar informasi kepada dosen tidak perlu lagi secara manual.

3. Agar sistem dapat berjalan lancer perlu adanya beckup data secara berkala. Selain mengindari kerusakan data juga agar data tidak hilang dan dapat digunakan untuk kedepannya.

\section{Daftar Pustaka}

[1] Hasan, I., 2002, Pokok - Pokok Materi Teori Pengambilan Keputusan, Ghalia Indonesia, Jakarta

[2] Jogiyanto Hartono, Mustakini, 2010, Metode Penelitian Sistem Informasi. Yogyakarta: Andi Offset.

[3] Kusrini,2007, Konsep dan Aplikasi Sistem Pendukung Keputusan, Yogyakarta, Penerbit Andi.

[4] Masngudi, 2000, Metode Penelitian, Jakarta , Universitas Borobudur.

[5] Sutanta, E., 2004, Sistem Basis Data, Graha Ilmu, Yogyakarta

[6] Yanti,N., \& Rahmadani, U.2014. Penyeleksian Calon Mahasiswa dengan Fuzzy Multi Attribute Decision Making Menggunakan TOPSIS. In K. Sredro (ed), Konferensi Nasional Sistem Informasi (hlm. 304-310).Makasar 